\title{
Over 25 years survival after Charnley's total hip arthroplasty
}

\author{
Jacques Caton • Jean Louis Prudhon
}

Received: 12 December 2010 / Accepted: 21 December 2010 / Published online: 21 January 2011

(C) The Author(s) 2011. This article is published with open access at Springerlink.com

\begin{abstract}
Background Since 1962, the low friction arthroplasty (LFA) developed by Sir John Charnley has spread widely throughout the world. Many series have reported long-term results. Polyethylene (PE) wear is well known. The average wear ratio is about $0.1 \mathrm{~mm}$ a year. Many factors may influence that wear process.

Purpose The authors describe two different series of patients operated upon with Charnley's total hip arthroplasty (THA) using the original cemented stem and a non modular 22.2-mm head, with a cemented full polyethylene acetabular socket. Outcomes confirm excellent patient function after 25 years. They emphasise the fact that $\mathrm{PE}$ is the weak point of total hip arthroplasty. Function may be excellent even though PE wear is significant. In several cases, no wear at the maximum follow-up was detectable. Results This study confirms different publications relating long-term follow-up with LFA. During a Charnley meeting in Lyon, we published a survival curve of $85 \%$ after 25 years. Berry et al. published a $86.5 \%$ survival curve (J Bone Joint Surg Am 84:171-177, 2002). In 1995, Luc and Marcel Kerboul published a 77\% survival rate after 20 years in young patients under 40 years old at the time of the surgery. In 2009, Callaghan et al. published a series of 35 years follow-up with a ratio of $78 \%$ survivorship ( $\mathrm{J}$ Bone Joint Surg Br 91:2617-2621).
\end{abstract}

\section{J. Caton}

Clinique Emilie De Vialar,

116 Rue Antoine Charial,

69003 Lyon, France

\section{J. L. Prudhon $(\bowtie)$}

Clinique des Cedres,

15 Rue Albert Londres,

38130 Echirolles, France

e-mail: jean-louis.prudhon@wanadoo.fr
Conclusion Could the long-term results be improved? Through recent decades, many solutions have been introduced to improve the survivorship of THA including bearing surfaces such as alumina-on-alumina and metal-on-metal. Different problems have occurred with these solutions. LFA might be improved by working on the nature and the quality of the head. Improvements might also be obtained by working on the quality and the hardness of the acetabular socket.

\section{Introduction}

Mid- and long-term follow-up of Charnley's hip arthroplasty demonstrates good functional results as shown in different studies. A French series from Lyon assessed an $85 \%$ survivorship at 25 years [5]. Older reported $96 \%$ after 25 years, while Berry et al. reported $86.5 \%$ [1], and Callaghan et al. found $78 \%$ survivorship after 35 years [2]. Wrobleski et al. reported Charnley low friction arthroplasty survival patterns to 38 years. They concluded that a regular follow-up after hip replacement is essential [7]. Both authors, Jacques Caton (Lyon study) and Jean Louis Prudhon (Grenoble study) followed-up two different series of long-term Charnley's hip arthroplasty [3-5].

The purpose of this study was to analyse function and radiological component status after very long-term followup (more than 25 years in the Lyon study and 30 years in the Grenoble study).

\section{First patient series from Grenoble}

Eighty-six Charnley's total hip arthroplasties (THA) implanted from January 1972 to December 1972 were followed-up in a retrospective study by J.L. Prudhon, MD. 
Data were collected in 2003 and 2004. All the implants were cemented original Charnley's components manufactured by Thackray's company Leeds, UK. Only two sizes of femoral components were available at that time. Two sizes of full polyethylene cemented acetabular cups were used. A senior surgeon, René Vidil, MD, performed all the procedures.

Surgery was routinely performed using Charnley's enclosure system with a general anaesthesia, through a postero lateral approach without capsular repair. The cementing technique used a high viscosity cement introduced into the femoral shaft with the fingers without pressurisation. The acetabular cup was implanted after reaming the acetabular bone with an expanding Charnley's reamer fixed in the acetabular bone through a central hole as described in original Charnley's technique. The hole was sealed with a metallic mesh "Mexican hat" included in the cement mantle.

Patients were discharged on average, 28 days after surgery. Full weight bearing was allowed after three weeks. Patients did not receive any antibiotics pre- or post-operatively.

\section{Material}

Eighty-six THA were performed between January 1972 and December 1972. Three patients had both hips replaced during this period. Nine patients had the contralateral hip replaced in 1973. Twelve patients had the contralateral hip replaced later on. Fifty patients were female, and 33 were male. The average age at surgery was 66 years, ranging from 54 to 84 .

The hip diseases were:

70 osteoarthrosis
five avascular osteonecrosis
three dysplasic osteoarthritis
one femoral neck fracture
two post-traumatic osteoarthritis
one rheumatoid arthritis
three hip osteotomy failure
one hip revision

Thirty-nine patients were totally and definitely lost for follow-up. Of these patients according to the patient chart we could see that two THA had been revised and one THA had been removed for deep infection. Information on those patients, excepted the three patients revised, who were lost to follow-up or suspected to have died was collected by mail or phone, extending the contact to the family or the general physician of their country. In 11 cases we were able to obtain information from the family after the patient had died. The replaced hip was still working nicely when the patient died in nine cases. One THA had been

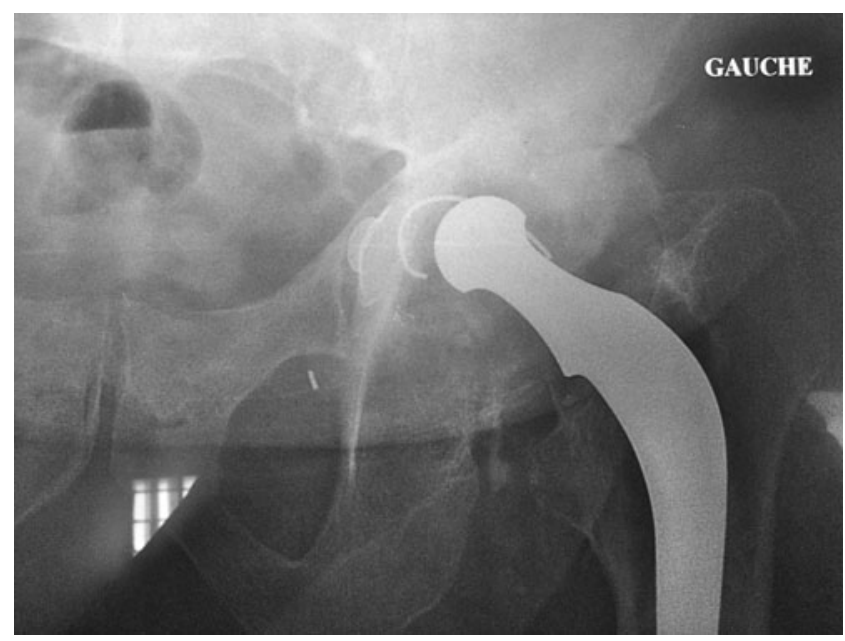

Fig. 1 Significant wear of the cup and femoral component loosening at 28 years post-op

revised by another team for loosening, and one case was removed due to a late infection. Forty-seven patients could be included in the long-term follow-up. Data were collected from the patient chart and the end point (patient death) was known. Two THAs had been revised for severe acetabular wear with bipolar loosening (Figs. 1 and 2).

One THA was simply removed because of late infection. Forty-four THA were still working with a good functional result. The average wear was between 1 and $3 \mathrm{~mm}$. There were no signs of loosening in either component. Three patients had recurrent dislocations but no revision surgery was performed because of the poor general health. Of these,

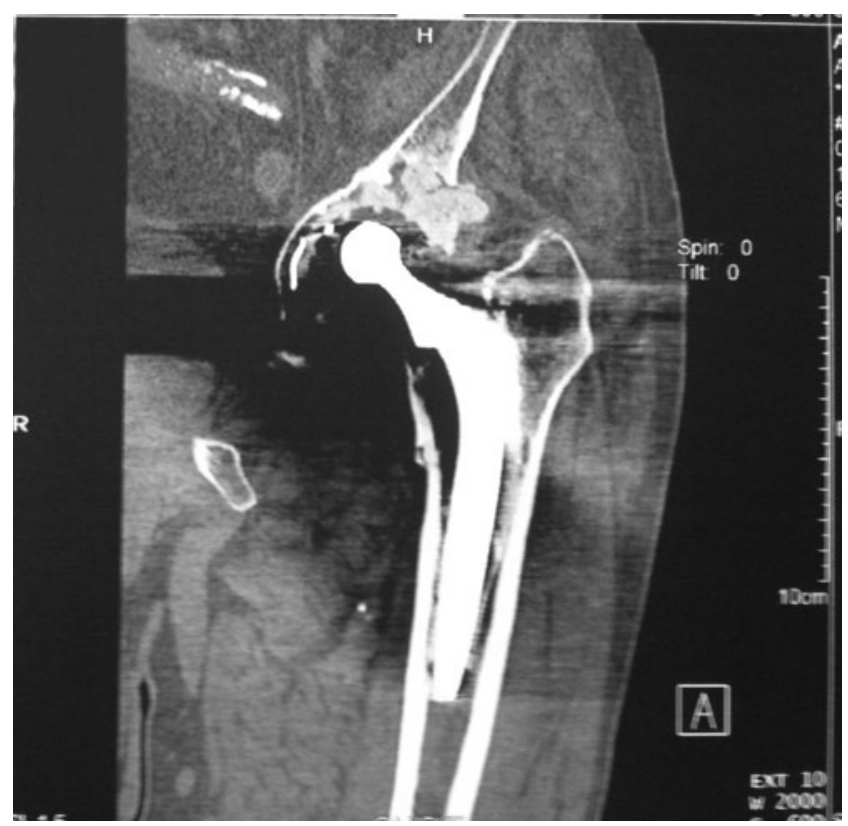

Fig. 2 Bone scan showing wear and loosening of both components after 26 years 


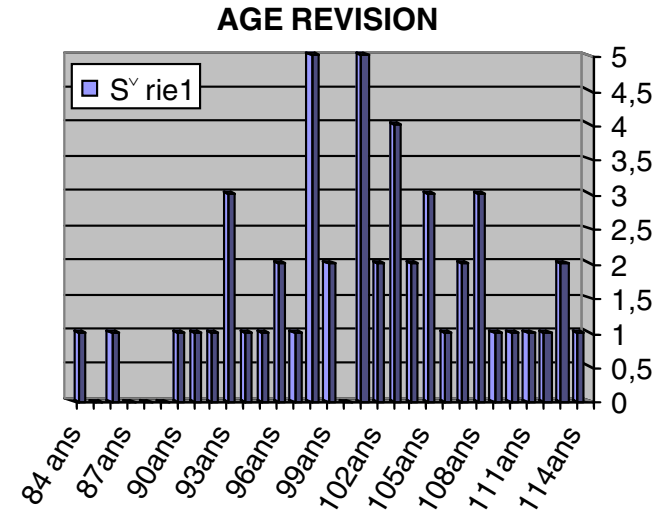

Graph 1 Expected age of the patients in 2004 patient series from Grenoble

two patients one had severe weight loss due to a neurological disease and two had significant cup wear, without loosening. Three patients are still alive. They are respectively 83,83 , and 85 years old. The THA is functioning well. There is no loosening nor are there radiolucent lines. The cup wear is $3 \mathrm{~mm}$ in one case and between 3 and $5 \mathrm{~mm}$ in two cases.

At the time of that study patients expected age would be between 88 to 113 years old with a median of 104 years (Graph 1).

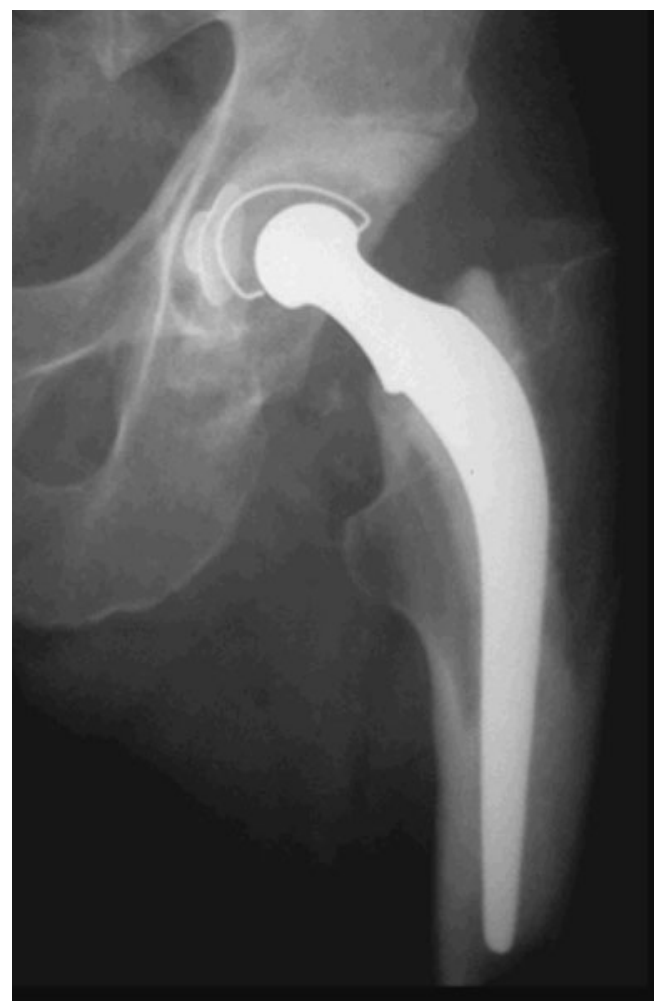

Fig. 3 No cup wear and no radiolucent lines at 30 years follow-up

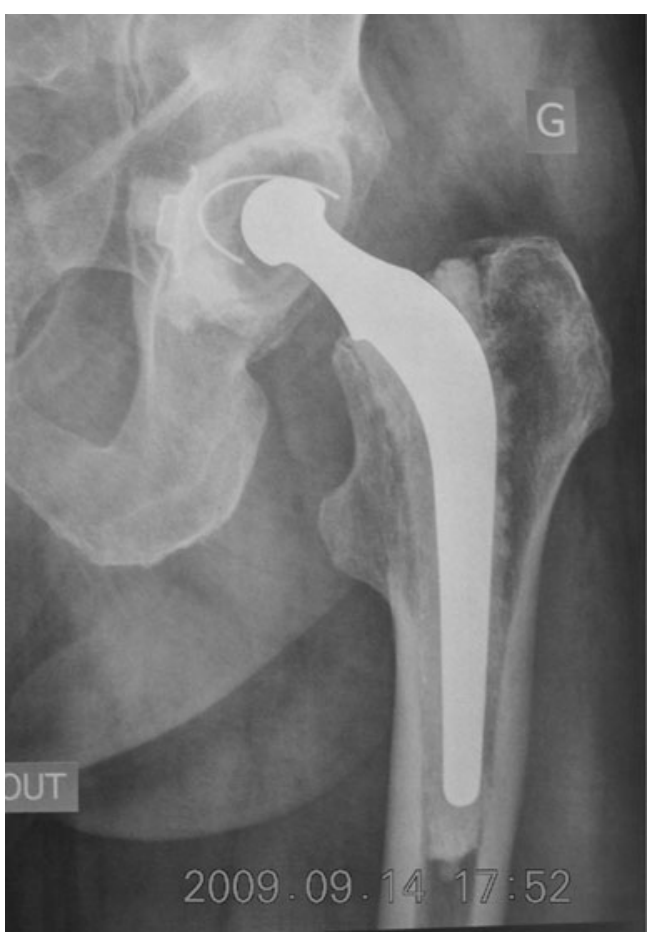

Fig. 4 No detectable wear after 30 years follow-up with original Charnley's total hip arthroplasty (THA)

\section{Second patient series from Lyon}

\section{Material}

We reviewed 25 patients operated upon from 1969 to 1974 by a senior surgeon, Pr. Claude Regis Michel, in the same conditions as patients from Grenoble with immediate full weight bearing. Thirty-seven hips have been replaced in 19

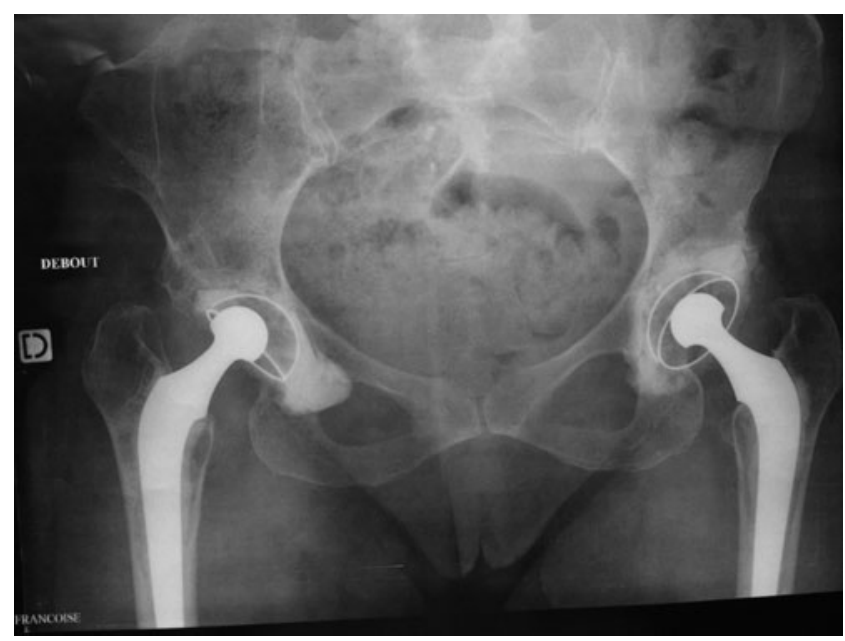

Fig. 5 Unpredictable wear process at 26 years follow-up in a female patient who was 36 years old at the time of surgery. The same surgeon and the same implants were used for both sides. The right hip was operated upon in January 1984, and the left in June 1984. Significant wear and a loosened cup occurred in the right hip. The cup was revised 
females and six males. Average body mass index was 26 . The preoperative function was evaluated according to the Merle D'Aubigne scoring system. The patient's age at surgery ranged from 37 to 73 with an average of 55 . The average pre op PMA score was 10.76. Mean follow-up was 26 years.

\section{Clinical results}

Four THA with severe cup wear and loosening of acetabular components have been revised after 17 years (one case), 24 years (two cases) and 31 years (one case). The average post op PMA score at last follow-up was 16.86 (range 14-18).

\section{Radiological results}

PE wear has been measured according to Livermore and Chevrot-Kerboul's methods. Cup wear ranged from $0 \mathrm{~mm}$ to $6.8 \mathrm{~mm}$. The median was $2.69 \mathrm{~mm}$. PE wear in this series was comparable with that observed in other LFA series $(0.1 \mathrm{~mm}$ a year).

Radiolucency had been analysed in 31 cases. Five cups demonstrated radiolucency in zone 1. In the femoral components, we could see lucent lines in Gruen's zone 1 in six cases and in zone 7 in eight cases. In two cases we noted heterotopic bone Brooker 1 in one case, and Brooker 2 in two cases.

\section{Discussion}

This study is anecdotal and emphasises how difficult it is to strictly follow-up patients following hip replacement as noted by M. Wrobleski [7]. At that time patients were not informed of the necessity to be reviewed with X-ray examination every two years.

PE wear is an unpredictable process. In all our different series of hip arthroplasty of full polyethylene cemented or uncemented metal back socket, the wear ranges were in three categories:

One third with an excessive wear pattern over $0.1 \mathrm{~mm}$ a year, with early revision.

One third with a "regular" wear pattern of $0.1 \mathrm{~mm}$ a year. Revision surgery needed after 25 years.

One third of patients with no wear at all. Wear undetectable during the life of the THA and patient death as the end point (Figs. 3 and 4).

Many factors can influence PE longevity. At the time of surgery PE was sterilised by a gamma irradiation process without vacuum protection. The head was finished by hand, and the sphericity of the ball could have influenced arthroplasty longevity (Fig. 5).

The revue also shows that many patients can derive functional benefits from Charnley's THA. First symptoms such as pain, dislocation and snapping regularly appear when the socket becomes loose and, as such, alert the patient.

\section{Conclusion}

All the long-term series have shown that PE wear is the weak point of joint replacement. Low friction arthroplasty can be considered a good and reliable solution for degenerative disease of the hip.

Will the new polyethylene be better in the future? Improvements in the PE manufacturing processes might be significant in the next few years according to the works of Triclot et al. [6].

Open Access This article is distributed under the terms of the Creative Commons Attribution Noncommercial License which permits any noncommercial use, distribution, and reproduction in any medium, provided the original author(s) and source are credited.

\section{References}

1. Berry DJ, Harmisen WS, Cabanela ME, Money BE (2002) Twenty five years survivorship of two thousand consecutive primary Charnley total hip replacements. J Bone Joint Surg Am 84:171-177

2. Callaghan JJ, Bracha P, Liu SS, Piyaworakkum S, Goetz DD, Johnston RC (2009) Survivorship of a Charnley total hip arthroplasty, a concise follow-up at a minimum of 35 years. Previous reports. J Bone Joint Surg Br 91:2617-2621

3. Caton J, Michel F, Picault Ch (1995) Charnley total hip arthroplasty 33 years of world wide experience. 2nd symposium Charnley International Lyon 1995. Edition Groupe ACORA, Lyon, pp 2530, 33-36, 71-78, 83-90

4. Caton J, Ferreira A, Picault Ch (2000) Arthroplastie totale de hanche. Quelle sera la prothèse du $21^{\circ}$ siècle? 3rd symposium Charnley International Lyon 2000. Edition Groupe ACORA, Lyon, pp 37-38, 99-109, 157

5. Caton J, Courpied JP, Ferreira A, Hamadouche M (2004) La prothèse totale de hanche. 4th symposium Charnley International Lyon 2004. Edition Groupe ACORA, MCI France, Lyon, pp 130-135, 77-78

6. Triclot P, Hamadouche M, Courpied JP (2007) A comparison of the penetration of two polyethylene acetabular liners of different levels of cross-linking. J Bone Joint Surg $\mathrm{Br}$ 89:1439-1445

7. Wrobleski BM, Siney PD, Fleming PA (2007) Charnley low friction arthroplasty-Survival patterns to 38 years. J Bone Joint Surg Br 39:1015-1018 